\begin{tabular}{|c|c|c|}
\hline+9 & $\begin{array}{l}\text { European Association for the } \\
\text { Development of Renewable Energies, Environment } \\
\text { and Power Quality (EA4EPQ) }\end{array}$ & $\begin{array}{l}\text { International Conference on Renewable Energies and Power Quality } \\
\text { (ICREPQ'12) } \\
\text { Santiago de Compostela (Spain), 28th to 30th March, } 2012\end{array}$ \\
\hline
\end{tabular}

\title{
Low-cost Online System for Detecting Unburned Fuel in a Large Industrial Biomass-fired Boiler
}

\author{
M. Liukkonen ${ }^{1}$, J. Huhtinen ${ }^{1}$, E. Hälikkä ${ }^{2}$, T. Hiltunen ${ }^{2}$ and Y. Hiltunen ${ }^{1}$ \\ ${ }^{1}$ Department of Environmental Science \\ University of Eastern Finland \\ Yliopistonranta 1, 70211 Kuopio (Finland) \\ Phone number:+358 40351 0644, e-mail: mika.liukkonen@uef.fi, yrjo.hiltunen@uef.fi \\ ${ }^{2}$ Foster Wheeler Ltd. \\ P.O. Box 201, 78201 Varkaus (Finland)
}

\begin{abstract}
Combustion of biomass is challenging due to the heterogeneous character of the fuel, which makes monitoring of the process important. Unburned carbon residue is one of the indicators of the inefficiency of the process, since it shows that the combustion has been incomplete. Nonetheless, there is a lack of measurements which could be used for monitoring the amount of unburned carbon in the bottom ash of energy boilers. In this paper we present a simple, low-cost online system for detecting unburned fuel, which has been tested on the bottom ash conveyor of a large-scale biomass-fired boiler. The system, which can be used for capturing online images from the process, includes an ordinary systems camera and a control computer placed in a protective case. The images are then analyzed and an index which indicates the amount of unburned carbon in the bottom ash is calculated. The results show that the system yields useful online information on the process, and a trend line can be used for monitoring the long-term changes. The system can be programmed to alarm when there is a growing trend in the carbon index, for example, and it has several potential applications in the future.
\end{abstract}

\section{Keywords}

Diagnostics, fluidized bed, unburned fuel, online inspection, image analysis

\section{Introduction}

Fuel flexibility and the ability to burn low-grade fuels are major advantages generally associated with fluidized bed combustion [1]-[2]. Because of these advantages, the fluidized bed seems to be one of the most suitable combustion technologies for converting biomass into energy [3]. Nonetheless, fuel flexibility also poses challenges. The use of demanding heterogeneous fuels such as biomass not only increases the need for monitoring the combustion process, but also complicates the development of new methods for diagnosing it.

Bed diagnostics is becoming an ever more important part of fluidized bed combustion of biomass. Coarsening of the bed material, for example, may lead to incomplete combustion, decreased efficiency, an increased level of emissions and even to agglomeration of bed material. This can cause serious problems such as unscheduled downtimes of the plant. On the other hand, unburned carbon in the bottom ash is an indicator of incomplete combustion and therefore an inefficient process. For these reasons diagnosing the bed quality is extremely important.

Diagnosing the quality of the bed material in fluidized bed boilers is usually performed manually by sieving the bottom ash. This is expensive and laborious, however, and should be automated if possible. Another possibility is to develop new computational tools, soft sensors, which rely on measurement data and which can be used in compensating or replacing difficult and expensive measurements. Soft sensors have been developed for estimating the bed quality [4]-[5], but they have certain weaknesses and limitations, which include the need for example data (i.e. manually acquired sieving data), the demands for the quality of the data, and process dynamics, which can complicate the development of the soft sensor.

The general target for measuring or analyzing unburned carbon in energy plants is the fly ash (See e.g. [6]-[8]). The other typical approaches for estimating the amount of unburned carbon in the fly ash has been modelling by using physical models [9], data mining [10] or their 
combination. Characterization of unburned carbon present in the solid or gaseous combustion products is, of course, also possible by performing laboratory analyses [11]-[12]. It seems, however, that there is not a widely-recognized method to monitor the amount of unburned carbon in the solid combustion products such as bottom ash of energy boilers.

In this paper we present a low-cost online inspection system for detecting unburned fuel in a biomass-fired energy boiler using a methodology which can be fully automated. The system consists of an ordinary systems camera which is automated to snap images over the bottom ash conveyor of a large-scale circulating fluidized bed boiler fired by biomass. The images are then analyzed to detect the unburned fuel particles and to calculate an index which indicates the amount of unburned carbon in the ash.

\section{Materials and methods}

\section{A. Case process}

The case process is a $385 \mathrm{MW}_{\text {th }}$ large-scale industrial boiler. The boiler is fired by biomass or a mixture of biomass and peat. The biomass consists of forest residue (bark, branches, crowns, stumps etc.). The plant produces steam and electricity for a pulp and paper plant and electricity and district heat for an energy company.

\section{B. Measurement system}

A low-cost industrial camera system was developed to learn whether digital images could be used to monitor the properties of the ash and to detect unburned carbon. The system includes a commercial systems camera and a mobile measuring and analyzing unit for capturing online images from the process (See Figure 1). The infrared motion sensor can be used to detect motion and shoot pictures at the right moment. The ordinary systems camera is located in a pressurized and sealed box to endure harsh and dirty conditions present in the industry. The total material cost of the system depends mainly on the camera used.

The automatically taken images can be forwarded to the control room PC via a WLAN router, for example, to be viewed and analyzed. The system has been tested in an industrial CFB boiler. The system installation over a bottom ash conveyor of a $385 \mathrm{MW}_{\text {th }} \mathrm{CFB}$ is presented in Figure 2.

\section{Image data}

Research on image processing and analysis methods was carried out to obtain information from image data. Main stages of the image acquisition and processing were:

1) Automated snapping of images in target plant

2) Image transfer to a remote server located at the university via a wireless connection

3) Image analysis

Images were taken from the process during one month in the spring of 2011. After the measurement period the system had collected 1019 digital images from the process, which yields approximately 33 images per day on an average.

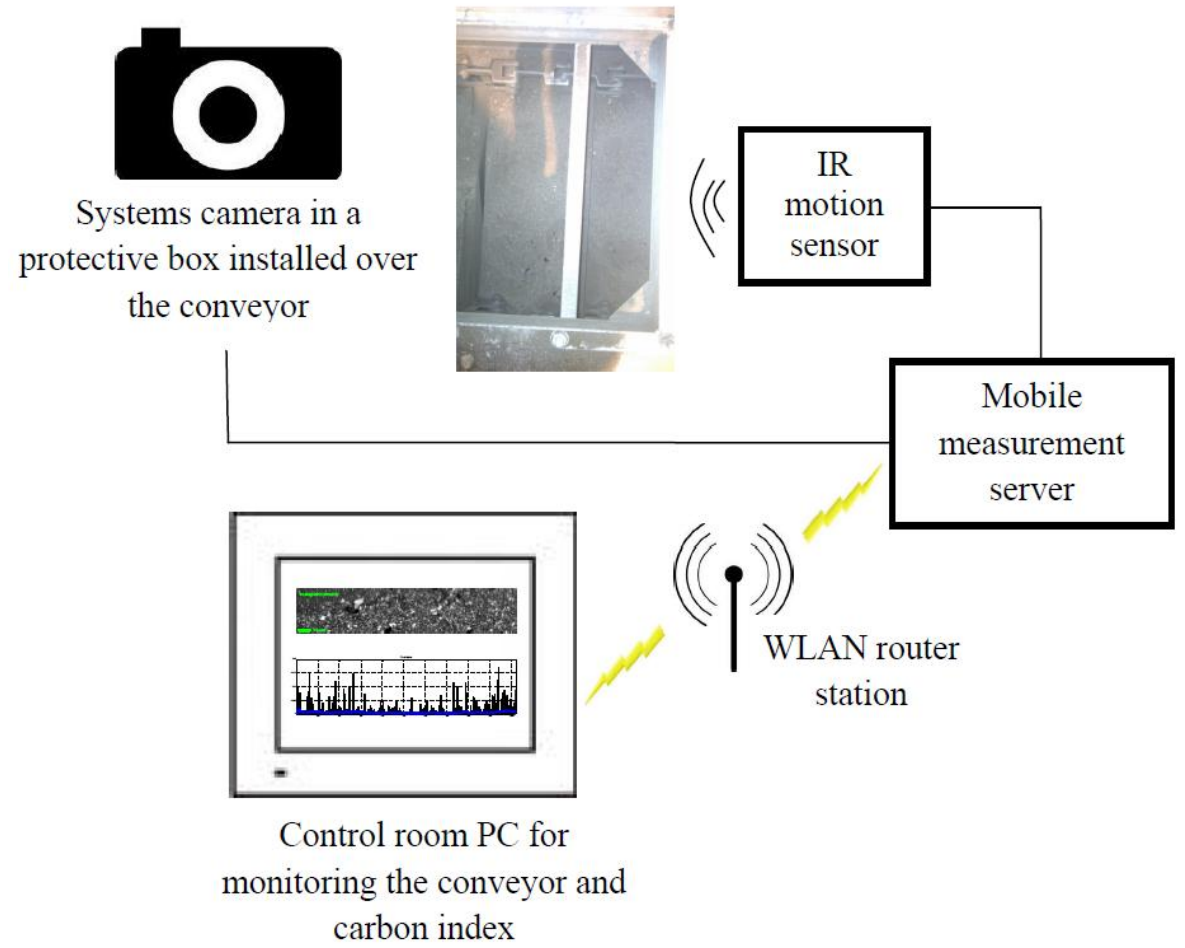

Fig. 1. An example implementation of the industrial camera system for monitoring unburned fuel in the bottom ash carried by the scraper conveyor of an energy boiler. 


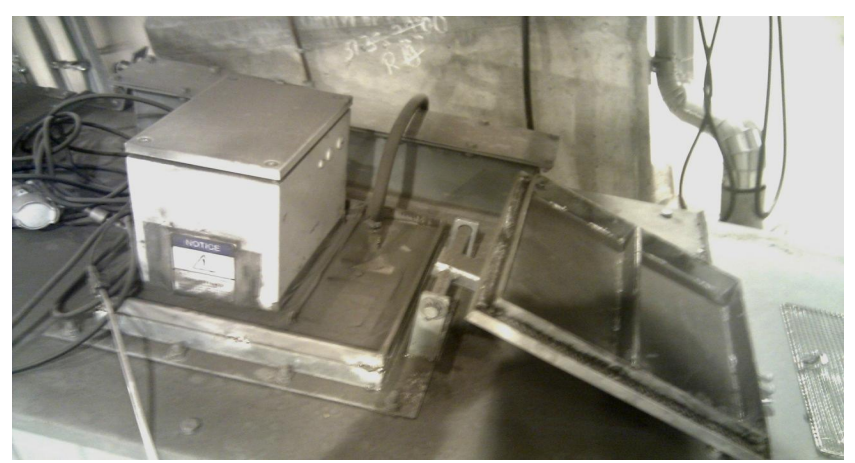

Fig. 2. Installation of the camera system over the bottom ash conveyor of a large-scale CFB fired by biomass.

\section{Processing of images}

There are a large number of image processing tools which can potentially be used for preparing digital images for the measurement of the features and structures they reveal [13]. Analysis of ash images taken from a conveyor is a relatively difficult problem due to many real-world challenges: the environment is dusty and dirty, the illumination can be poor, particles are small and overlap with each other, material is in layers, moving structures of the conveyor can appear in the images, and so on. Fortunately, computational processing of images makes it possible to solve many of these problems.

The purpose of the study was to create an index which would indicate the amount of unburned fuel in the bottom ash. The stages for determining the carbon index are as follows:

1) Convert the colour image to grayscale image

2) Adjust contrast

3) Convert to binary image (by using a fixed threshold with a low value)

4) Remove small objects to remove noise
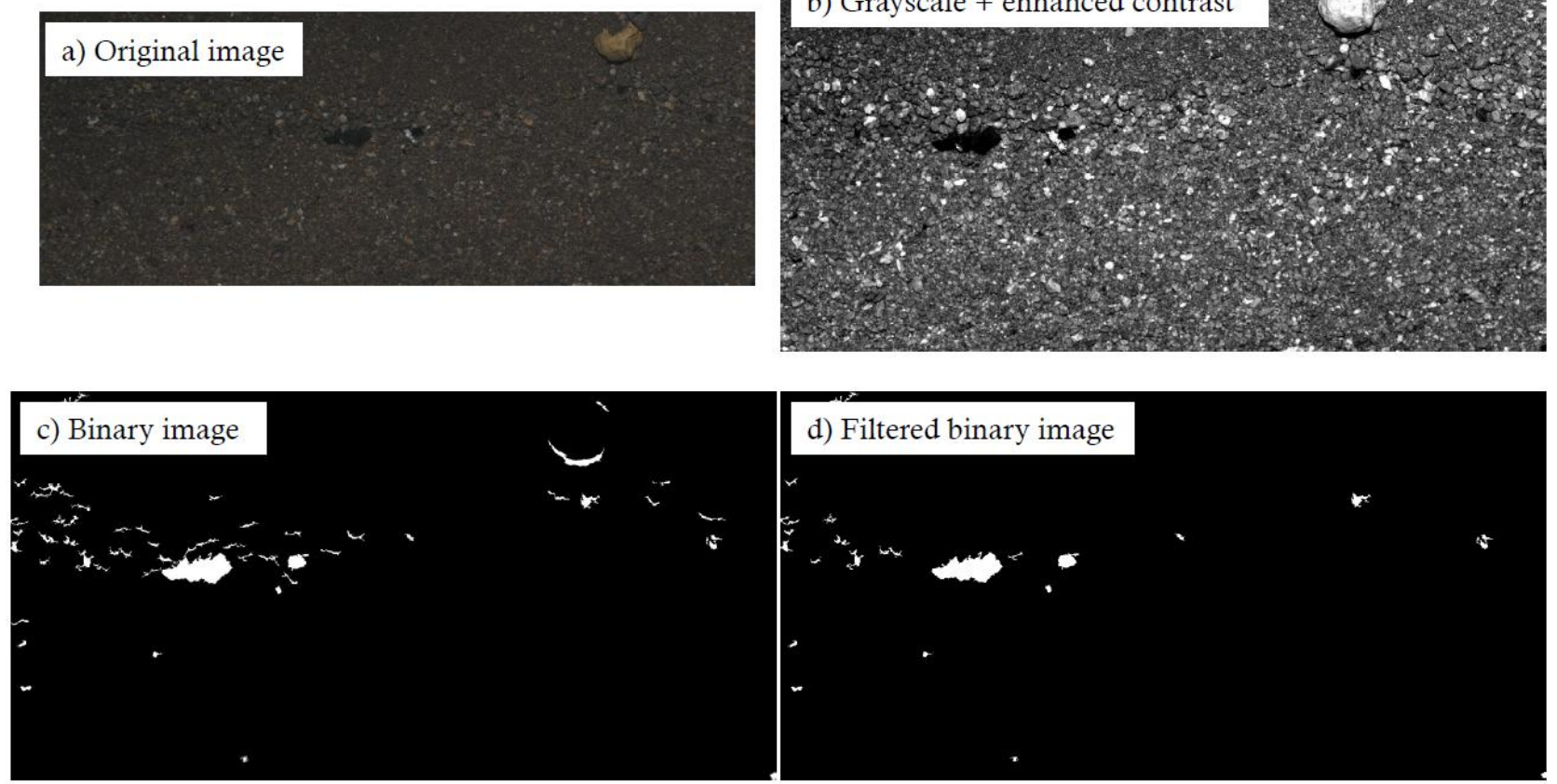

Fig. 3. Pre-processing of an ash image before carbon analysis. a) the original image taken from the bottom ash conveyor, b) image

converted to grayscale and contrast enhanced, c) image converted to a binary form, and d) filtered binary image.

5) Find connected components (=objects)

6) Filter objects to remove shadows (See Figure 3 for stages 1-6)

7) Calculate object areas (in pixels)

8) Calculate carbon index as in (1)

$$
\sum\left(A_{\text {carbon }}\right) / \sum\left(A_{\text {all pixels }}\right)
$$

where $A_{\text {carbon }}$ is the total area of detected objects in pixels and $A_{\text {all pixels }}$ denotes the total number of pixels in an image.

First the digital colour image is converted to a grayscale image, and its contrast is adjusted to allow the automatic object detection perform better in the later stages of the analysis. Next, the image is converted into a binary image. The objective of binarization is to separate features representing the objects from the background, so that they can be measured and counted [13]. At this stage small objects (i.e. $<800$ pixels, which is approximately $0.1 \%$ of the total number of pixels in an image) are removed to reduce noise in the pixel data.

The next step in the analysis is to search for pixels connected to each other to identify the black objects potentially representing unburned carbon particles. Here we use 8-neighborhood in detecting the connected pixels, which means that there are eight possible directions for connectivity in a two-dimensional space.

As we can see in Figure 3c, the binary image still comprises objects which can be erroneously classified as unburned carbon particles, while in reality they are merely object shadows caused by poor lighting conditions. Therefore a filtration procedure based on the object shape is implemented at this stage, which improves the detection and makes the identification of carbon objects more reliable (See Figure 3d).

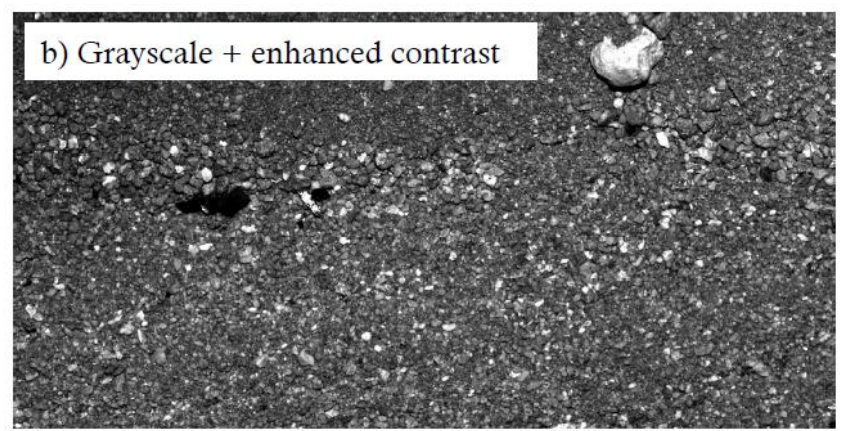


Finally, a simple index indicating the amount of carbon in the bottom ash is calculated by dividing the total area of identified carbon particles by the total number of pixels in the digital image.

\section{Results and discussion}

An online inspection system for detecting unburned fuel in a biomass-fired energy boiler has been developed using a methodology which can be fully automated. The purpose was, on one hand, to construct a low-cost pilot system which could be used to test the potential of the approach with minimal investment costs, and on the other hand, to see if some of the technical limitations of a relatively cheap camera could be compensated with more advanced image processing and a simple protective case which makes the harsh conditions suitable for the camera. The current material cost of the whole system, which consists mainly of the purchase price of the systems camera, would be around $500 €$ which is much below the price of traditional industrial cameras and makes the system an economically competitive option for industrial process monitoring.

Despite the low material cost, the results achieved by the system were promising. The carbon index calculated for each image analyzed during the measurement period is presented in Figure 4. The images corresponding to the highest values of the index are shown in Figure 5.

It can be seen in Figure 4 that both short- and long-term changes can be detected in the carbon index. Two or three occasions in which the index has been increasing during a longer period of time can be distinguished in the trend line, but overall the amount of unburned carbon, and especially the baseline of the carbon index, seems to remain low in this one-month measurement period. In the middle part of the month there seems to be a period in which the carbon index has remained on a relatively low level. On the other hand, the lack of real problems in the measurement period makes it difficult to draw any conclusions on the operation of the system in a problematic situation. Furthermore, because there were not any appreciable problems in the operation of the boiler during the period, this far we have not been able to determine what the acceptable limit for the unburned carbon would be in this case.

It is important to note that the material is in layers on the conveyor (the thickness of the ash bed can be a couple of centimetres), so some particles inevitably remain undetected if they are located below the surface. On the other hand, in case that the number of carbon particles is high, it is also more probable that they appear also on the surface. In other words, one can assume that the topmost layer is a sample which represents all of the material.

The approach presented for inspecting the unburned fuel is useful, because merely a sheer online image from the conveyor, updated and transferred to control room PC, would enable the process personnel to monitor the process and to take necessary actions when sudden problems occur. In addition, the calculation of carbon index makes it possible to monitor long-term trends and helps in detecting possible problems evolving during a longer period of time. Furthermore, the system makes it possible to develop an early warning system which would alert in a problematic case, but to achieve this more tests would be needed to determine which the acceptable limit for the grain index actually is.

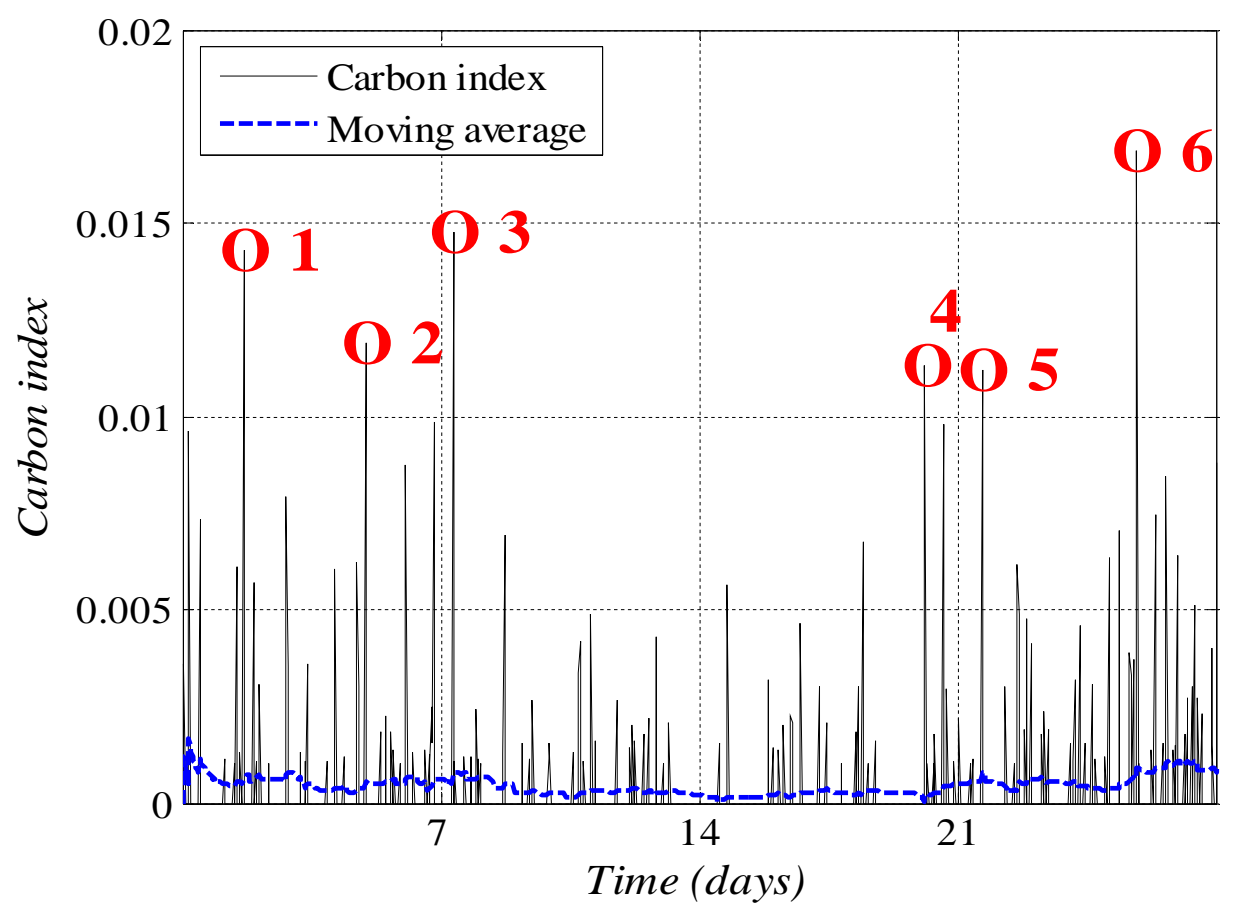

Fig. 4. Carbon index and its trend line covering a one-month period of operational use of the boiler. The points marked with red rings represent the single images presented in Fig. 5. 

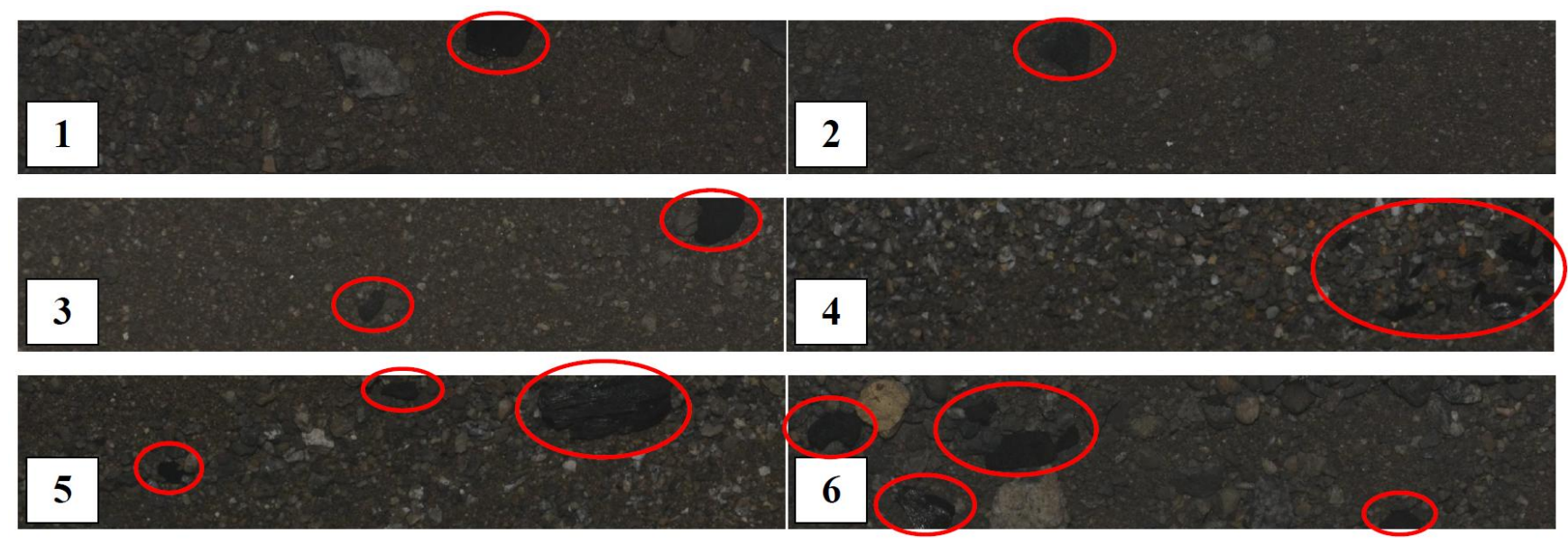

Fig. 5. Six images indicating a high amount of unburned fuel particles (marked with red rings). The numbers refer to the red marks presented in Figure 4.

\section{Conclusions}

A low-cost online inspection system for detecting unburned fuel in an energy boiler has been developed. The benefits of the measurement system include:

- Only one calibration is needed (focusing of the camera).

- Camera and other instruments are all available from public consumer market, which ensures low material costs.

- The system is compact and easy to install.

- The system is applicable to dusty and dirty industrial environments due to the pressurized and sealed enclosure.

The main conclusions from testing the industrial camera system in the CFB boiler are:

- An ordinary digital camera can be used for getting quality pictures from the ash flow of an energy boiler.

- Image analysis enables the monitoring of the amount of unburned fuel in the bottom ash.

- The system provides online information on the process, and trend lines can be used to monitor changes occurring during a longer period of time.

- The system can be programmed to alarm in case there is a growing trend in the carbon index, for example (early warning system).

- The system has several other possible future applications such as monitoring the coarseness of bed material or quality control of solid fuels before combustion.

\section{Acknowledgement}

The authors would like to thank the Finnish Funding Agency for Technology and Innovation (Tekes) for funding the research project Dynergia.

\section{References}

[1] P. Basu, Combustion of coal in circulating fluidized-bed boilers: a review, Chemical Engineering Science, Vol. 54 (1999), pp. 5547-5557.

[2] J. Koornneef, M. Junginger, and A. Faaij, Development of fluidized bed combustion - An overview of trends, performance and cost, Progress in Energy and Combustion Science, Vol. 33 (2007), pp.19-55.

[3] J. Sandberg, C. Karlsson, and R.B. Fdhila, A 7 year long measurement period investigating the correlation of corrosion, deposit and fuel in a biomass fired circulated fluidized bed boiler, Applied Energy, Vol. 88 (2011), pp. 99-110.

[4] M. Liukkonen, E. Hälikkä, T. Hiltunen, and Y. Hiltunen, "Adaptive Soft Sensor for Fluidized Bed Quality", in: Proc. Impacts of Fuel Quality on Power Production \& Environment [CD-ROM], paper 19. Electric Power Research Institute (EPRI) (2010).

[5] M. Liukkonen, E. Hälikkä, T. Hiltunen, and Y. Hiltunen, Adaptive Soft Sensor for Fluidized Bed Quality: Applications to Combustion of Biomass, Fuel Processing Technology (in press) (2011).

[6] V.S Batra, S. Urbonaite, and G. Svensson, Characterization of unburned carbon in bagasse fly ash, Fuel, Vol. 87 (2008), pp. 2972-2976.

[7] D. Clifford, Measuring Unburned Carbon in Flyash with an Automated On-line Monitor, Power Engineering, Vol. 112 (2008), pp. 40-44.

[8] H. Liu, H. Tan, Q. Gao, X. Wang, and T. Xu, Microwave attenuation characteristics of unburned carbon in fly ash, Fuel, Vol. 89 (2010), pp. 3352-3357.

[9] J. Pallarés, I. Arauzo, E. Teruel, Development of an engineering system for unburned carbon prediction, Fuel, Vol. 88 (2009), pp. 187-194.

[10] T. Jin and Z. Fu, Application of data mining in power plant unburned carbon in fly ash modelling, in Proc. 7th International Conference on Fuzzy Systems and Knowledge Discovery, FSKD 2010, pp. 2761-2765.

[11] L. Bartoňová, Z. Klika, and D.A. Spears, Characterization of unburned carbon from ash after bituminous coal and lignite combustion in CFBs, Fuel, Vol. 86 (2007), pp. 455463.

[12] N.J. Wagner, R.H. Matjie, J.H. Slaghuis, and J.H.P. van Heerden, Characterization of unburned carbon present in coarse gasification ash, Fuel, Vol. 87 (2008), pp. 683-691.

[13] J.C. Russ, The Image Processing Handbook, $6^{\text {th }}$ edition, CRC Press, Boca Raton (2011). 